\title{
A Preliminary Report on Brain- Derived Extracellular Vesicle as Novel Blood Biomarkers for Sport-Related Concussions
}

\author{
Keisuke Kawata ${ }^{1 *}$, Masato Mitsuhashi ${ }^{2}$ and Randy Aldret ${ }^{3}$ \\ ${ }^{1}$ Department of Kinesiology, School of Public Health-Bloomington, Indiana University, Bloomington, IN, United States, \\ ${ }^{2}$ NanoSomiX Inc., Aliso Viejo, CA, United States, ${ }^{3}$ School of Kinesiology, University of Louisiana at Lafayette, Lafayette, \\ $L A$, United States
}

OPEN ACCESS

Edited by:

Firas H. Kobeissy, University of Florida,

United States

Reviewed by:

Eric Peter Thelin,

University of Cambridge,

United Kingdom

Ralph George Depalma,

US Department of Veterans

Affairs, United States

David W. Nelson,

Karolinska Institute (KI), Sweden

*Correspondence:

Keisuke Kawata

kkawata@indiana.edu

Specialty section: This article was submitted

to Neurotrauma,

a section of the journal

Frontiers in Neurology

Received: 15 January 2018 Accepted: 26 March 2018

Published: 12 April 2018

Citation:

Kawata K, Mitsuhashi M and Aldret $R$ (2018) A Preliminary Report on

Brain-Derived Extracellular Vesicle as Novel Blood Biomarkers for Sport-Related Concussions.

Front. Neurol. 9:239. doi: 10.3389/fneur.2018.00239
The purpose of the study was to test the utility of unique panel of blood biomarkers as a means to reflect one's recovery process after sport-related neurotrauma. We established a panel of biomarkers that reacted positive with CD81 (extracellular vesicle marker) and various neuron- and glia-specific antigens [e.g., neurofilament light polypeptide (NF-L), tau, synaptosome-associated protein 25 (SNAP25), glial fibrillary acidic protein, and myelin basic protein]. We first evaluated test-retest reliabilities of brain-derived exosome markers, followed by an application of these markers in eight professional ice hockey players to detect cumulative neuronal burden from a single ice hockey season. During the season, two players were diagnosed with concussions by team physician based on an exhibition of symptoms as well as abnormality in balance and ocular motor testing. One player reached symptom-free status 7 days after the concussion, while the other player required 36 days for symptoms to completely resolve. Blood samples and clinical assessments including balance error scoring system and near point of convergence throughout recovery process were obtained. Biomarkers indicative of axonal damage, neuronal inflammation, and glial activation showed excellent test-retest reliabilities (intraclass correlation coefficient: $0.713-0.998, p$ 's $<0.01$ ). There was a statistically significant increase in the NF-L marker at post-season follow-up compared to pre-season baseline $(Z=-2.100, P=0.036)$; however the statistical significance did not withstand Bonferroni correction for multiple comparisons. In concussion cases, neuronal and microglia markers notably increased after concussions, with the unique expression patterns being similar to that of concussion recovery process. These longitudinal data coupled with excellent test-retest reliabilities of novel array of blood biomarkers potentially reflect the damage in neural cell structures and metabolic crisis due to concussion. However, future studies with larger sample size and appropriate control groups to evaluate sensitivity and specificity of these markers are needed. This preliminary case report suggests the potential utility of multimodal blood biomarkers for concussion prognosis and recovery assessment.

Keywords: mild traumatic brain injury, concussion, neurotrauma, ice hockey, subconcussion, microvesicle

\section{INTRODUCTION}

Mild traumatic brain injury (mTBI) presenting with negative intracranial bleeding, often referred to as concussion, is the most common neurological injury. The majority of patients with concussion eliciting symptoms (e.g., headache, dizziness, and light sensitivity) and behavioral abnormality (e.g., balance and eye tracking) recover within a 7- to 14-day period, while approximately $15 \%$ of 
patients exhibit lingering signs and symptoms beyond 2 weeks $(1,2)$. Outward symptoms are thought to be the most direct method to evaluate individual's well-being. However, emerging evidence indicates that neural cell damage and healing process do not correlate with symptom scores, such that, microstructural damage and functional impairment persist even after complete resolution of concussion-related symptoms (3-5). Therefore, an objective panel of assessments that are highly sensitive and specific to the extent of cellular damage is needed for "at risk" individuals such as athletes and military service members.

The use of blood biomarkers is known to be a promising avenue as they enable the detection of subtle cellular, structural, and metabolic changes after neural damage $(6,7)$. Elevations in protein-based biomarkers including tau protein, neurofilament light polypeptide (NF-L), glial fibrillary acidic protein (GFAP), S100-beta, $a$ II-Spectrin N-terminal fragment, and ubiquitin C-terminal hydrolase L1 have been observed in concussion patients across ages, injury mechanisms, and occupations, indicating their immense utility in concussion diagnosis (8-15). These markers are predominantly expressed by brain parenchymal cells and known to reflect an acute phase of neuronal damage and glial activation, by exponentially increasing their expressions in the brain and bloodstream. However, because the vast majority of these serological factors, with NF-L as an exception $(16,17)$, have short plasma half-lives $(<6 \mathrm{~h})$ due to protease degradation and filtrations by kidney and liver ( 7 ), there are significant limitations in their prognostic value and longitudinal utility after concussions.

To overcome these limitations, cellular vesicles such as exosomes have emerged as a novel means of detecting a wide array of diseases in oncology, cardiovascular, and neuroscience communities, given that exosomes are continuously detectable from cells undergoing activation, injury, inflammation, or infection (18-20). In the present study, we captured a double-positive signal containing $\mathrm{CD} 81^{+}$, exclusively expressed on the surface of extracellular vesicles such as exosomes $(21,22)$, and cell-specific antigens for neuron, astrocyte, oligodendrocyte, and microglia, respectively. We first examined the test-retest reliability of the panel of serological signals containing both $\mathrm{CD} 81^{+}$and cellular factors from neurons, astrocytes, oligodendrocytes, and microglia in healthy individuals at three time points in 2 weeks. Second, changes in the biomarker profile between pre- and post-season were evaluated in professional ice hockey players, aiming to assess neural burden from a single hockey season. Finally, the biomarker patterns from the two players with concussions who showed highly different recovery time courses and profiles were reported.

\section{MATERIALS AND METHODS}

\section{Experimental Design and Participants}

For the reliability study, we collected blood samples once a week for three times from six healthy adults (four females and two males; age: $31.5 \pm 15.1$ years) who have no history of brain injury or neurological defects. For the concussion study, we recruited eight professional ice hockey players (eight males; age: $26.63 \pm 1.6$ years; body mass index: $25.97 \pm 1.65 \mathrm{k} / \mathrm{m}^{2}$ ) and a pair of plasma samples from pre-season baseline and post-season follow-up of the 2015-2016 ice hockey season was obtained. During the course of the season, two concussion cases were identified: subject 3 (concussion case \#1) with a complete symptom resolution by 7 days after concussion, while subject 6 (concussion case \#2) persisted his concussion symptoms until 36 days after concussion (2). Plasma samples along with clinical data were collected until full return-to-play with no symptoms. For the concussion case \#1, data points were at 3, 9, and 17 days post-concussion as well as post-season time point corresponding to 130 days post-concussion. For the concussion case \#2, data points were at 1, 9, 16, 22, 29, 36, 43, and 50 days post-concussion as well as post-season time point corresponding to 57 days postconcussion. The University of Louisiana Lafayette Institutional Review Board approved the study, and the participants gave written informed consent.

\section{Clinical Assessments}

Near point of convergence (NPC) was assessed based on our established protocol $(23,24)$. Briefly, the accommodative ruler (Gulden Ophthalmics, Elkins Park, PA, USA) rested on the player's upper lip, and an accommodative target (reduced-size Snellen chart) was moved down the length of the ruler toward the eyes at a rate of approximately $1-2 \mathrm{~cm} / \mathrm{s}$. NPC was taken when the tester observed eye misalignment or when participants verbally signaled experiencing diplopia. On verbal signal, the tester stopped moving the target and recorded the distance between the participant and object. Test was repeated twice, and the average value was used for analysis.

Balance error scoring system (BESS) is a valid series of three balance tasks (25). These tasks were performed first on a firm surface and standardized close-cell foam mat (Airex AG, Switzerland). The three-balance tasks included $2 \mathrm{ft}$ together stance, single-leg non-dominant side stance, and tandem stance with the dominant foot forward. The subjects performed these six tasks with their eyes closed over a single $20 \mathrm{~s}$ trial. A single tester counted errors during the trial using established criteria (25). Upon completion of the six tasks, a floor and mat score was calculated for each player. Both NPC and BESS data were obtained by one trained individual for all participants, including all time points from the concussed players.

\section{Blood Sampling of Healthy Participants and Ice Hockey Players}

For both the reliability and concussion studies, $10 \mathrm{~mL}$ of venous blood was drawn into vacutainer sterile tubes containing $0.5 \mathrm{~mL}$ saline with EDTA and centrifuged for $15 \mathrm{~min}$ at $2,500 \times g$ and $4^{\circ} \mathrm{C}$. Plasmas were stored in $0.5 \mathrm{~mL}$ aliquots at $-80^{\circ} \mathrm{C}$.

\section{ELISA Detection and Quantification of Serological Factors}

Monoclonal antibodies were biotinylated by mixing with EZ-Link Sulfo-NHS-LC-Biotin (Thermo Fisher Scientific) at room temperature for $30 \mathrm{~min}$, followed by the purification of antibodies by spin columns, according to the instruction manual of the product. 
We selected the following plain monoclonal antibodies against neuron-specific proteins [synaptosome-associated protein 25 (SNAP25), NF-L, tau, and SYP], astrocyte-specific proteins (EAAT1 and GFAP), oligodendrocyte-specific proteins (OMG $\mathrm{MBP})$, microglia-macrophage-specific protein (CD11b), and cytokines [interleukin 8 (IL8) and tumor necrosis factor alpha $(\mathrm{TNF} \alpha)$ ] (Santa Cruz Biotechnology, Dallas, TX, USA), as well as exosome-enriched marker CD81 (LSBio, Seattle, WA, USA).

The principle of our sandwich ELISA is to capture neuron-, astrocyte-,oligodendrocyte-, andmicroglia/macrophage-derived materials directly from plasma on the ELISA wells, where antiSNAP25, anti-EAAT1, anti-OMG, and anti-CD11b antibodies (Santa Cruz Biotechnology, Dallas, TX, USA) are immobilized, respectively. Plasma samples were further reacted with biotinylated antibody against CD81 (LSBio). Our targets were doublepositive signals, $[\mathrm{CD} 81]_{\mathrm{SNAP} 25+}$ for neuronal origin, $[\mathrm{CD} 81]_{\mathrm{EAAT} 1+}$ for astrocyte origin, [CD81 $]_{\mathrm{OMG}+}$ for oligodendrocyte origin, and $[\mathrm{CD} 81]_{\mathrm{CD} 1 \mathrm{lb}+}$ for microglia origin. Separately, SNAP25 plates were reacted with biotinylated antibodies against various neuronal proteins (NF-L, tau) as well as cytokines (TNF $\alpha$ and IL8), and we named them $[\mathrm{NF}-\mathrm{L}]_{\mathrm{SNAP} 25+}$, $[\mathrm{Tau}]_{\mathrm{SNAP} 25+},[\mathrm{TNF} \alpha]_{\mathrm{SNAP} 25+}$, and [IL8 $]_{\mathrm{SNAP25}}$, respectively. Similarly, EAAT1 plates and OMG plates were reacted with biotinylated antibodies against astrocyte-specific protein GFAP and oligodendrocyte-specific protein $\mathrm{MBP}$, respectively, and the results are named as $[\mathrm{GFAP}]_{\mathrm{EAAT} 1+}$ and $[\mathrm{MBP}]_{\mathrm{OMG}+}$. Anti-CD11b antibody is expressed in microglia as well as peripheral blood macrophages. Yet, double-positive signals of both CD11b and neuron-specific protein, SYP, suggest microglial phagocytosis of damaged neurons, named as $[\mathrm{SYP}]_{\mathrm{CD} 1 \mathrm{~b}+}$. These markers were normalized by $[\mathrm{CD} 81]_{\mathrm{SNAP} 25+}$ for neuronal double-positive markers (i.e., [NF-L $]_{\mathrm{SNAP} 25+}$ ), $[\mathrm{CD} 81]_{\mathrm{EAAT} 1+}$ for astrocyte $\left([\mathrm{GFAP}]_{\mathrm{EAAT} 1+}\right),[\mathrm{CD} 81]_{\mathrm{OMG}+}$ for oligodendrocyte $\left([\mathrm{MBP}]_{\mathrm{OMG}+}\right)$, or $[\mathrm{CD} 81]_{\mathrm{CD} 1 \mathrm{~b}+}$ for microglia $\left([\mathrm{SYP}]_{\mathrm{CD} 11 \mathrm{~b}+}\right)$ markers. For instance, dividing $[\mathrm{NF}-\mathrm{L}]_{\mathrm{SNAP} 25+}$ by neuron-related exosomes $[\mathrm{CD} 81]_{\mathrm{SNAP} 25+}$ yields the values of NF-L per neuron-related exosome. In other words, non-normalized values $\left([\mathrm{NF}-\mathrm{L}]_{\mathrm{SNAP} 25+}\right)$ are the amount in plasma, and normalized values $\left([\mathrm{NF}-\mathrm{L}]_{\mathrm{SNAP25}} /[\mathrm{CD} 81]_{\mathrm{SNAP} 25+}\right)$ are the amount per neuronrelated exosome.

Various antibodies were suspended in 1X coating buffer and applied to white eight-well strips in a final volume of $50 \mu \mathrm{L}$. After $1 \mathrm{~h}$ of incubation at room temperature, each well was washed once with $1 \mathrm{X}$ wash buffer, then $75 \mu \mathrm{L}$ of blocker casein solution supplemented with $0.5 \%$ BSA (Equitech) was added into each well for blocking. After another $1 \mathrm{~h}$ of incubation at room temperature, each well was washed twice with $1 \mathrm{X}$ wash buffer, then $40 \mu \mathrm{L}$ of plasma samples was added into each well. Plasma was diluted in PBS without any detergent and incubated in a refrigerator overnight. Next day, each well was washed twice with $1 \mathrm{X}$ wash buffer, then $40 \mu \mathrm{L}$ of biotinylated antibody solution supplemented with $4 \mu \mathrm{g} / \mathrm{mL}$ mouse IgG and 1\% BSA (Thermo Fisher Scientific) in $0.1 \%$ tween 20 -PBS was added, and incubation was continued at room temperature for $1 \mathrm{~h}$. After washing, $40 \mu \mathrm{L}$ of SA-HRP supplemented with $5 \%$ blocker casein and $0.25 \%$ BSA (Equitech) in $0.1 \%$ tween 20 -PBS was added, and incubation was continued at room temperature for the final $30 \mathrm{~min}$. After washing, $50 \mu \mathrm{L}$ of SuperSignal (Thermo Fisher Scientific) was added, and chemiluminescent signals [relative light units (RLU)] were determined in a luminometer (ANSH Labs, Webster, TX, USA).

To quantify the signals, we assigned $100 \mathrm{U} / \mathrm{mL}$ to a positive control sample, a dilution study was conducted in each ELISA to obtain RLU in each dilution. Then, using four-parameter logistic analysis, the RLU of each sample was converted to units per millilitre.

\section{Protein Biomarker Assay}

Plasma samples from two concussion cases were analyzed for protein biomarkers including tau, NF-L, GFAP (Millipore, Billerica, MA, USA), TNF $\alpha$, and IL8 (Quanterix, Lexington, MA, USA) using commercially available ELISA kits. Fluorescent signals measured by a microplate reader (BioTek EL800, Winooski, VT, USA) were converted into $\mathrm{ng} / \mathrm{mL}$ as per standard curve concentrations. The experimenter performing the assay was blinded from subject information.

\section{Statistical Analyses}

A series of Shapiro-Wilk tests revealed that a data set was not well-modeled by a normal distribution. Therefore, Friedman tests were conducted to examine a stability of biomarker expressions, followed by an individual intraclass correlation coefficient (ICC) to assess test-retest reliabilities across three time points (26). Using a two-way mixed-effects analysis of variance model, we estimated the ICC for baseline (day 0) to week 1 (day 7) and for week 1 (day 7) to week 2 (day 14). ICC is conceptually positive between 0 (not reliable at all) and 1 (perfectly consistent between repeated measurements), but its estimation can be negative in a few cases. We put the negative ICC values to be zeros as commonly done by various studies $(27,28)$. Based on the value of ICC, reliability is often categorized as poor (ICC $=0-0.2)$, fair (0.2-0.4), moderate (0.4-0.6), substantially good (0.6-0.8), and excellent (>0.8) (29). Next, Wilcoxon signed-rank tests were used to evaluate the changes in biomarker levels between pre-season baseline and post-season follow-up in professional ice hockey players. All data analyses were conducted using SPSS (version 25.0; SPSS Inc., Chicago, IL, USA), and statistical significance was set at $a \leq 0.05$.

\section{RESULTS}

\section{Standard Curves}

ELISA readings (RLU) of each biomarker level were successfully converted to units per millilitre by using standard curves yielded from the preliminary dilution study, as illustrated in Figure S1 in Supplementary Material.

\section{Fluctuation of Plasma Levels of Biomarker Expressions}

Levels of all biomarkers were widely spread among six healthy subjects over $2-3$ logs. After normalization by $[\mathrm{CD} 81]_{\mathrm{SNAP} 25+}$ for neuronal-, $[\mathrm{CD} 81]_{\mathrm{EAAT} 1+}$ for astrocyte-, [CD81 $]_{\mathrm{OMG}+}$ for oligodendrocyte-, or $[\mathrm{CD} 81]_{\mathrm{CD} 1 \mathrm{~b}+}$ for microglia-related markers, such variations reduced to 1-2 logs (Figures S2 and S3 in Supplementary Material). Friedman tests showed no statistically 
significant difference between each time point. The test-retest reliability across three time points showed an excellent agreement for virtually all markers (Table 1), indicating a minimum withinsubject fluctuation over time.

\section{Changes of Biomarkers Before and After Ice Hockey Season}

Wilcoxon signed-rank test indicated that there was a significant increase in $[\mathrm{NF}-\mathrm{L}]_{\mathrm{SNAP} 25+} /[\mathrm{CD} 81]_{\mathrm{SNAP} 25+}$ at post-season compared to pre-season baseline $(Z=-2.100, P=0.036)$; however, the statistical significance did not withstand Bonferroni correction for multiple comparisons. All other markers also failed to reach statistical significance (Table 2). Individual expression levels are listed in Table 3. It is worth noting that subject 1, who had four previous concussions, showed greater than a threefold increase in neuronal markers $\left([\mathrm{NF}-\mathrm{L}]_{\mathrm{SNAP} 2+} /[\mathrm{CD} 81]_{\mathrm{SNAP} 25+},[\mathrm{Tau}]_{\mathrm{SNAP}_{25+} /} /\right.$ $[\mathrm{CD} 81]_{\mathrm{SNAP} 25+},[\mathrm{TNF} \alpha]_{\mathrm{SNAP} 25+_{+}} /[\mathrm{CD} 81]_{\mathrm{SNAP} 25+}$, and $[\mathrm{IL} 8]_{\mathrm{SNAP}_{25+}} /$ $\left.[\mathrm{CD} 81]_{\mathrm{SNAP25+}}\right)$, as well as oligodendrocyte markers $\left([\mathrm{MBP}]_{\mathrm{OMG}+} /\right.$ $\left.[\mathrm{CD} 81]_{\mathrm{OMG}+}\right)$. Subject 4 , who had one previous concussion, also showed more than a 2.5 -fold increase in neuronal markers (Table 3).

\section{Reports of two Concussion Cases Case 1: Transient Defects}

The concussion case 1 (subject 3 ) sustained a concussion in-game from a hockey puck traveling at a high rate of speed that struck him near the chin on his goalie mask. This initial blow caused him to fall backwards toward the goal and hit the back of his head on the crossbar. He lost his consciousness for 15-20 s. The patient regained consciousness shortly after the athletic trainer arrived. During the transport on a spine board, he again lost consciousness for 15-20 s. Diagnostics, including MRI and CT imaging, were performed with no substantial findings, and he was released later that evening.

Post-concussion patterns observed in subject 3 was consistent with current consensus, where $85-90 \%$ of concussion patients resolve symptoms and normalize clinical tests to their baseline levels within 1-2 weeks $(2,30,31)$. His symptoms dissipated by day 7 , but increased errors in BESS and worsening in NPC were observed through days 3-9 after concussion and normalized to the baseline level by day 17 (Figure 1A). Circulating biomarkers, on the other hand, have shown a different pattern from the clinical measures. The levels of $[\mathrm{NF}-\mathrm{L}]_{\mathrm{SNAP}_{25}+} /[\mathrm{CD} 81]_{\mathrm{SNAP} 25+}$, $[\mathrm{TNF} \alpha]_{\mathrm{SNAP} 25+} /[\mathrm{CD} 81]_{\mathrm{SNAP} 25+}$, and $[\text { IL8 }]_{\mathrm{SNAP} 25+} /[\mathrm{CD} 81]_{\mathrm{SNAP} 25+}$ (Figures 1E,G,H) slowly increased up to day 17 after concussion. The level of $[\mathrm{SYP}]_{\mathrm{CD} 11 \mathrm{~b}+} /[\mathrm{CD} 81]_{\mathrm{CD} 11 \mathrm{~b}+}$ (Figure 1K) showed a $422 \%$ increase at day 17 after concussion compared to the baseline. All the other markers showed an unremarkable pattern (Figures 1B-D, F, I, J).

\section{Case 2: Persisted Symptoms}

The concussion case 2 (subject 6) sustained a mild, glancing blow to the right temporal area of the head during a slow pace practice drill. The patient had no loss of consciousness and mild symptoms initially. Over the next few days, the patient began to develop a significant headache, balance issues during activities of daily living, and an aversion to loud, sudden noises. His concussion symptoms-particularly, headache and sensitivity to noise-persisted for more than a month and resolved at day 36 after concussion. NPC slowly increased and peaked at day 36 after concussion (Figure 2A) and returned to the baseline levels by day 57 . MRI at day 36 showed no abnormality. Substantial biphasic increases, peaked at day 50 , were observed in $[\mathrm{NF}-\mathrm{L}]_{\mathrm{SNAP} 25+} /[\mathrm{CD} 81]_{\mathrm{SNAP} 25+},[\mathrm{Tau}]_{\mathrm{SNAP} 25+} /$ $[\mathrm{CD} 81]_{\mathrm{SNAP25+}},[\mathrm{TNF} \alpha]_{\mathrm{SNAP}_{25}+} /[\mathrm{CD} 81]_{\mathrm{SNAP} 25+}$, and $[\mathrm{IL} 8]_{\mathrm{SNAP} 25+} /$ $[\mathrm{CD} 81]_{\mathrm{SNAP}_{25}}($ Figures 2E-K). Such drastic changes in the neuronal

TABLE 1 | Stability of biomarker levels across three time points.

\begin{tabular}{|c|c|c|c|c|c|c|}
\hline \multirow[t]{2}{*}{ Markers } & \multirow[t]{2}{*}{$\chi^{2}$} & \multirow[t]{2}{*}{$\boldsymbol{P}$} & \multicolumn{2}{|c|}{ Baseline to day 7} & \multicolumn{2}{|c|}{ Day 7 to day 14} \\
\hline & & & ICC $(95 \% \mathrm{CI})$ & $P$ & ICC $(95 \% \mathrm{CI})$ & $P$ \\
\hline [CD81]SNAP25+ & 4.000 & 0.135 & $0.902(0.389,0.986)$ & 0.013 & $0.883(0.328,0.983)$ & 0.014 \\
\hline$[N F-L]_{\text {SNAP25+ }}$ & 1.249 & 0.328 & $0.989(0.908,0.998)$ & $<0.001$ & $0.980(0.879,0.997)$ & $<0.001$ \\
\hline$[\text { Tau }]_{\text {SNAP25+ }}$ & 0.783 & 0.676 & $0.992(0.949,0.999)$ & $<0.001$ & $0.971(0.810,0.996)$ & 0.001 \\
\hline$[T N F \alpha]_{\text {SNAP25+ }}$ & 0.333 & 0.846 & $0.998(0.985,1.000)$ & $<0.001$ & $0.996(0.974,0.999)$ & $<0.001$ \\
\hline$[\mathrm{IL} 8]_{\text {SNAP25+ }}$ & 0.333 & 0.846 & $0.995(0.969,0.999)$ & $<0.001$ & $0.985(0.903,0.998)$ & $<0.001$ \\
\hline$[N F-L]_{\text {SNAP } 25+} /[\text { CD81 }]_{\text {SNAP } 25+}$ & 3.037 & 0.094 & $0.974(0.556,0.997)$ & $<0.001$ & $0.948(0.462,0.993)$ & 0.001 \\
\hline$[\mathrm{Tau}]_{\mathrm{SNAP} 25+} /[\mathrm{CD} 81]_{\mathrm{SNAP} 25+}$ & 5.333 & 0.069 & $0.832(0,0.977)$ & 0.048 & $0.729(0,0.960)$ & 0.024 \\
\hline$[T N F \alpha]_{\text {SNAP } 25+/[C D 81]_{\text {SNAP } 25+}}$ & 4.333 & 0.115 & $0.829(0,0.976)$ & 0.015 & $0.729(0,0.959)$ & 0.050 \\
\hline$[\text { [L8 }]_{\text {SNAP25+ }} /[\text { CD81 }]_{\text {SNAP25+ }}$ & 4.000 & 0.135 & $0.947(0.685,0.992)$ & 0.003 & $0.944(0.425,0.993)$ & 0.001 \\
\hline$[C D 81]_{\text {EAAT1+ }}$ & 0.333 & 0.846 & $0.759(0,0.965)$ & 0.071 & $0.784(0,0.968)$ & 0.043 \\
\hline$[\text { GFAP }]_{\text {EAAT }+}$ & 2.333 & 0.311 & $0.923(0.545,0.989)$ & 0.006 & $0.893(0.367,0.985)$ & 0.010 \\
\hline$[\mathrm{GFAP}]_{\text {EAAT1+ }} /[\mathrm{CD} 81]_{\mathrm{EAAT} 1+}$ & 0.333 & 0.846 & $0.897(330,0.985)$ & 0.015 & $0.969(0.776,0.996)$ & 0.001 \\
\hline$[\mathrm{CD} 81] \mathrm{OMG}^{+}$ & 1.708 & 0.230 & $0.900(0.378,0.986)$ & 0.013 & $0.845(0.132,0.977)$ & 0.023 \\
\hline$[\mathrm{MBP}]_{\mathrm{OMG}+}$ & 4.000 & 0.135 & $0.971(0.825,0.996)$ & 0.001 & $0.988(0.931,0.998)$ & $<0.001$ \\
\hline$\left.[\mathrm{MBP}]_{\mathrm{OMG}} / / \mathrm{CD} 81\right]_{\mathrm{OMG}+}$ & 5.695 & 0.095 & $0.713(0,0.957)$ & 0.080 & $0.817(0,0.974)$ & 0.014 \\
\hline$[\mathrm{SYP}]_{\mathrm{CD} 11 \mathrm{~b}+} /[\mathrm{CD} 81]_{\mathrm{CD} 11 \mathrm{~b}+}$ & 0.333 & 0.846 & $0.915(0.481,0.988)$ & 0.009 & $0.922(0.528,0.989)$ & 0.005 \\
\hline
\end{tabular}

$\chi^{2}$ values and corresponding $P$ values were obtained from Friedman tests. Intraclass correlation coefficient was conducted to examine test-retest reliabilities of each biomarker. Cl, confidence interval; SNAP25, synaptosome-associated protein 25, NF-L, neurofilament light polypeptide; TNF $\alpha$, tumor necrosis factor-alpha; IL8, interleukin-8; EAAT1, excitatory amino acid transporter 1; GFAP, glial fibrillary acidic protein; OMG, oligodendrocyte myelin glycoprotein; MBP, myelin basic protein; SYP, synaptophysin. 
markers reflected throughout post-concussion recovery period, while imaging analysis (MRI) failed to detect any changes.

\section{Analysis of Protein-Based Biomarkers in two Concussion Cases}

Circulating protein expressions of tau, NF-L, GFAP, TNF $\alpha$, and IL8 were assessed in the two concussion cases. There was no remarkable trend for all biomarkers, with the expression levels being widely fluctuated across recovery time points (Figure 3).

TABLE 2 | Changes in exosome markers between pre- and post-season.

\begin{tabular}{|c|c|c|}
\hline Exosome markers & Pre-season $(n=8)$ & Post-season $(n=8)$ \\
\hline [CD81]SNAP25+ & 4.39 (7.72) & $3.22(4.54)$ \\
\hline$[\mathrm{NF}-\mathrm{L}]_{\mathrm{SNAP} 25+} /[\mathrm{CD} 81]_{\text {SNAP } 25+}$ & $12.58(11.89)$ & $21.65(15.90)$ \\
\hline$[\mathrm{Tau}]_{\mathrm{SNAP25+}} /[\mathrm{CD} 81]_{\mathrm{SNAP} 25+}$ & $3.25(2.07)$ & $4.60(2.91)$ \\
\hline$[\mathrm{TNF} \alpha]_{\text {SNAP25+ }} /[\mathrm{CD} 81]_{\text {SNAP } 25+}$ & $10.75(10.78)$ & $16.30(12.04)$ \\
\hline$[\mathrm{IL} 8]_{\mathrm{CD} 81+\mathrm{SNAP} 25+} /[\mathrm{CD} 81]_{\mathrm{SNAP} 25+}$ & $13.68(13.34)$ & 23.64 (19.68) \\
\hline$[C D 81]_{\text {EAAT1+ }}$ & $6.56(10.04)$ & $7.12(12.32)$ \\
\hline$[\mathrm{GFAP}]_{\text {EAAT } 1+} /[\mathrm{CD} 81]_{\text {EAAT } 1+}$ & $5.89(9.43)$ & $4.59(4.34)$ \\
\hline$[\mathrm{CD} 81]_{\mathrm{OMG}+}$ & $8.36(11.56)$ & $8.42(13.27)$ \\
\hline$[\mathrm{MBP}]_{\mathrm{OMG}}+[\mathrm{CD} 81]_{\mathrm{oMG}+}$ & $15.61(20.74)$ & $25.49(28.18)$ \\
\hline$[S Y P]_{C D 11 b+} /[C D 81]_{C D 11 b+}$ & $40.40(31.85)$ & $45.66(46.70)$ \\
\hline
\end{tabular}

Mean units per millilitre $(S D)$

Results showed no significant difference in all markers between pre- and post-season SNAP25, synaptosome-associated protein 25, NF-L, neurofilament light polypeptide; TNF $\alpha$, tumor necrosis factor-alpha; IL8, interleukin-8; EAAT1, excitatory amino acid transporter 1; GFAP, glial fibrillary acidic protein; OMG, oligodendrocyte myelin glycoprotein; MBP, myelin basic protein; SYP, synaptophysin.

\section{DISCUSSION}

We reported unique profiles of blood biomarkers for two cases of concussion as well as pre- and post-season changes in professional ice hockey players. The major findings of the present studies are that an array of biomarkers including neuronal- and microglia origin increased after concussions, with the unique expression patterns being similar to that of concussion recovery process. Excellent test-retest reliabilities of these markers further underpin that the robust increases observed in concussed individuals are potentially due to the damage in neural cell structures and metabolic crisis. To our knowledge, this is the first case report demonstrating an array of blood biomarkers to gradually raise in concert with clinical measures in two of the concussion cases.

To date, there are no biomarkers including NF-L, tau, TNF $\alpha$, IL8, and SYP that are useful in a longitudinal approach because of their relatively short plasma half-lives. To overcome this major limitation, we targeted serological factors that are reacted positive with CD81 and various neuron-specific and inflammatory antigens. It is highly plausible that the detected signals are circulating exosomes containing neuron- and glia-specific factors on their surface. Exosomes (30-100 nm in diameter) are a mode of intercellular communication that shuttles vesicles containing bioactive molecules (e.g., proteins, mRNA, and microRNA) from one cell to another through interstitial fluid for proximal cells and the blood stream for distant recipients (32). During the genesis of exosomes, portions of the plasma membrane are internalized as endosomes or intraluminal endosomal vesicles within the host cells. Bioactive products are packed inside the vesicles, while

TABLE 3 | Individual profiles of biomarker expressions between pre- and post-season (dark shade, drastic increase possibly due to brain trauma; gray shade, increase not related to brain trauma).

\begin{tabular}{|c|c|c|c|c|c|c|c|c|c|c|c|c|c|c|c|c|c|}
\hline \multirow[b]{2}{*}{$\mathbf{n}$} & \multicolumn{2}{|c|}{ Concussion } & \multicolumn{3}{|c|}{$[C D 81]_{\text {SNAP25+ }}$} & \multicolumn{3}{|c|}{$\begin{array}{l}\text { [NF-L] }]_{\text {SNAP25+ }} / \\
{[\mathrm{CD} 81]_{\text {SNAP25+ }}}\end{array}$} & \multicolumn{3}{|c|}{$\begin{array}{c}{[\mathrm{Tau}]_{\mathrm{SNAP25}} /} \\
{[\mathrm{CD} 81]_{\mathrm{SNAP25+}}}\end{array}$} & \multicolumn{3}{|c|}{$\begin{array}{c}{[\mathrm{TNF} \alpha]_{\text {SNAP } 25+} /} \\
{[\mathrm{CD} 81]_{\mathrm{SNAP} 25+}}\end{array}$} & \multicolumn{3}{|c|}{$\begin{array}{c}{[\mathrm{IL8}]_{\mathrm{SNAP25}} /} \\
{[\mathrm{CD} 81]_{\mathrm{SNAP25+}}}\end{array}$} \\
\hline & Previous & This season & Pre & Post & Fold & Pre & Post & Fold & Pre & Post & Fold & Pre & Post & Fold & Pre & Post & Fold \\
\hline 2 & 0 & 0 & 0.24 & 0.61 & 2.51 & 6.21 & 15.5 & 2.49 & 2.36 & 3.63 & $\overline{1.54}$ & 9.66 & 12.8 & 1.33 & 10.7 & 17.1 & $\overline{1.60}$ \\
\hline 3 & 2 & 1 & 23.2 & 13.4 & 0.58 & 2.86 & 6.40 & 2.24 & 2.15 & 2.43 & 1.13 & 2.30 & 3.92 & 1.71 & 2.42 & 4.76 & 1.97 \\
\hline 4 & 1 & 0 & 0.54 & 0.62 & 1.16 & 10.8 & 27.6 & 2.56 & 2.49 & 7.60 & 3.05 & 9.30 & 22.2 & 2.38 & 12.0 & 31.3 & 2.61 \\
\hline 7 & 2 & 0 & 4.28 & 6.29 & 1.47 & 3.38 & 3.48 & 1.03 & 1.74 & 1.99 & 1.14 & 2.58 & 2.68 & 1.04 & 2.52 & 3.04 & 1.21 \\
\hline \multirow[t]{2}{*}{8} & 0 & 0 & 2.16 & 1.86 & 0.86 & 16.7 & 16.9 & 1.01 & 3.08 & 3.09 & 1.00 & 11.5 & 12.3 & 1.07 & 17.2 & 15.5 & 0.90 \\
\hline & \multicolumn{2}{|c|}{ Concussion } & \multicolumn{3}{|c|}{$[C D 81]_{\text {EAAT1+ }}$} & \multicolumn{3}{|c|}{$\begin{array}{l}\text { [GFAP] }]_{\text {EAAT1 }+/} / \\
\text { [CD81] }]_{\text {EATT1+ }}\end{array}$} & \multicolumn{3}{|c|}{ [CD81]OMG ${ }^{+}$} & \multicolumn{3}{|c|}{$\begin{array}{l}{[\mathrm{MBP}]_{\text {ома }+} /} \\
{[\mathrm{CD} 81]_{\text {ома+ }}}\end{array}$} & \multicolumn{3}{|c|}{$\begin{array}{l}{[\mathrm{SYP}]_{\mathrm{CD} 11 b+} /} \\
{[\mathrm{CD} 81]_{\mathrm{CD} 11 \mathrm{~b}+}}\end{array}$} \\
\hline $\mathbf{n}$ & Previous & This season & Pre & Post & Fold & Pre & Post & Fold & Pre & Post & Fold & Pre & Post & Fold & Pre & Post & Fold \\
\hline 5 & 0 & 0 & 0.03 & 0.14 & 4.11 & 29.0 & 14.5 & 0.50 & 0.07 & 0.27 & 4.16 & 66.0 & 34.9 & 0.53 & 6.20 & 10.3 & 1.66 \\
\hline 6 & 1 & 1 & 2.72 & 0.60 & 0.22 & 3.90 & 4.67 & 1.20 & 4.83 & 0.69 & 0.14 & 13.2 & 32.9 & 2.50 & 89.5 & 31.6 & 0.35 \\
\hline 7 & 2 & 0 & 17.1 & 34.6 & 2.02 & 0.41 & 0.26 & 0.64 & 19.8 & 37.3 & 1.88 & 1.67 & 1.33 & 0.80 & 28.4 & 20.4 & 0.72 \\
\hline 8 & 0 & 0 & 2.61 & 2.53 & 0.97 & 3.64 & 3.11 & 0.86 & 5.20 & 4.67 & 0.90 & 7.88 & 9.16 & 1.16 & 60.0 & 50.2 & 0.84 \\
\hline
\end{tabular}

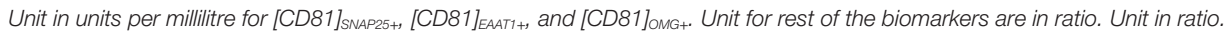

SNAP25, synaptosome-associated protein 25, NF-L, neurofilament light polypeptide; TNFo, tumor necrosis factor-alpha; IL8, interleukin-8; EAAT1, excitatory amino acid transporter 1; GFAP, glial fibrillary acidic protein; OMG, oligodendrocyte myelin glycoprotein; MBP, myelin basic protein; SYP, synaptophysin. 


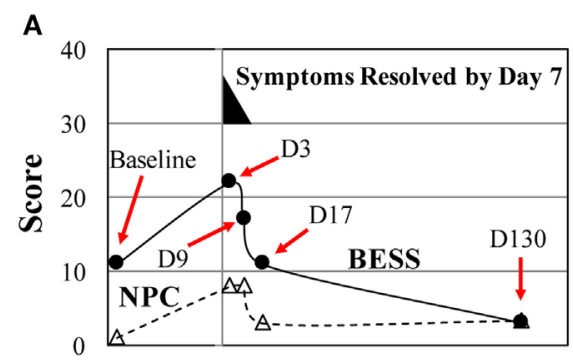

B
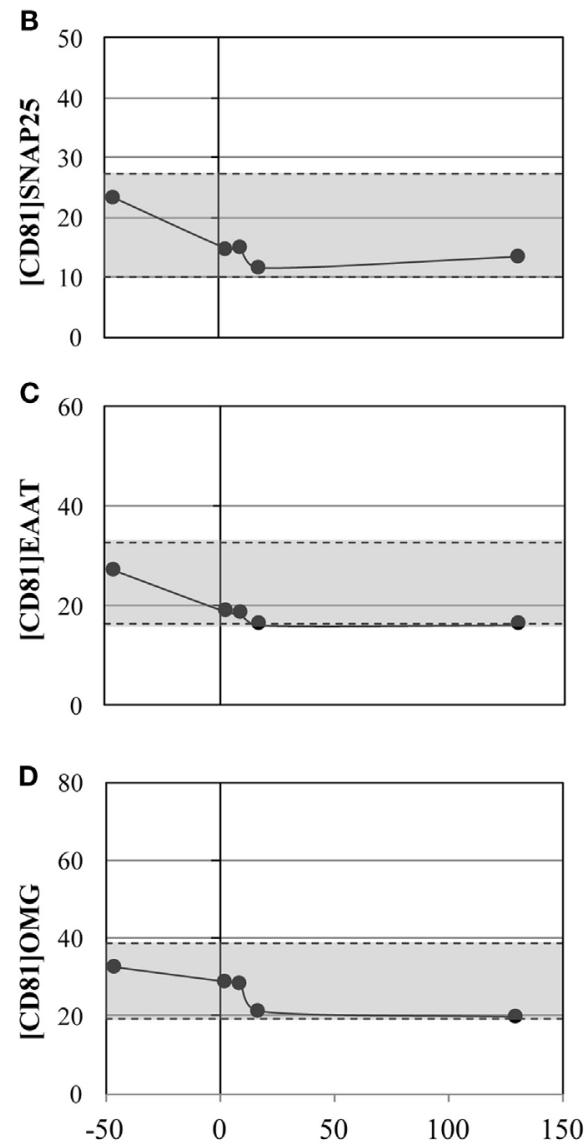

Days before and after concussion

\section{E}

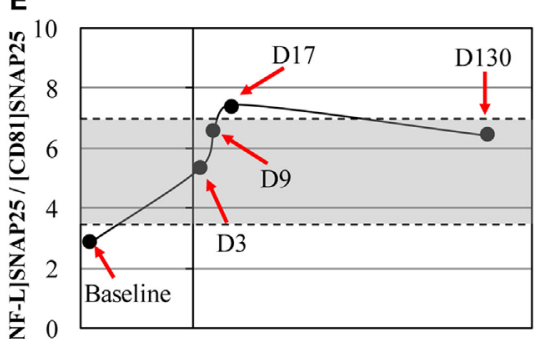

$\mathbf{F}$

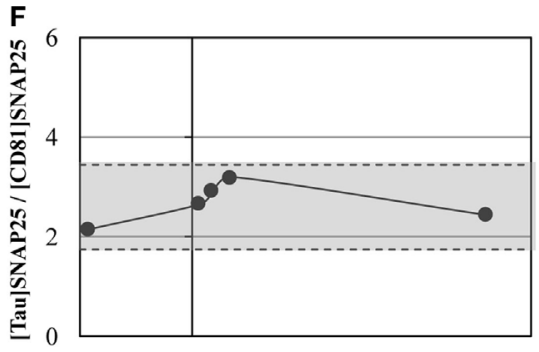

G

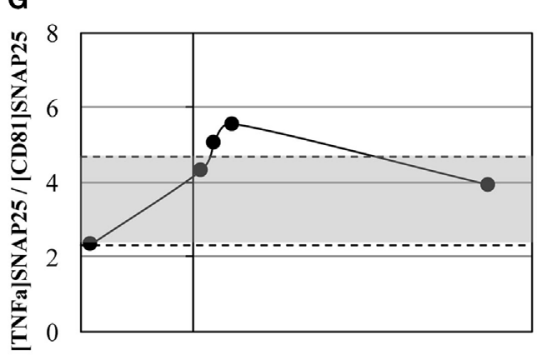

H

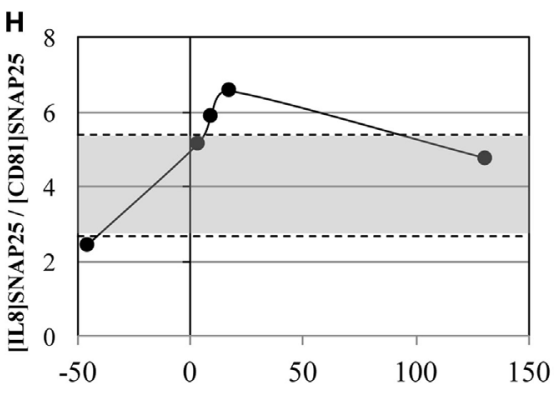

I
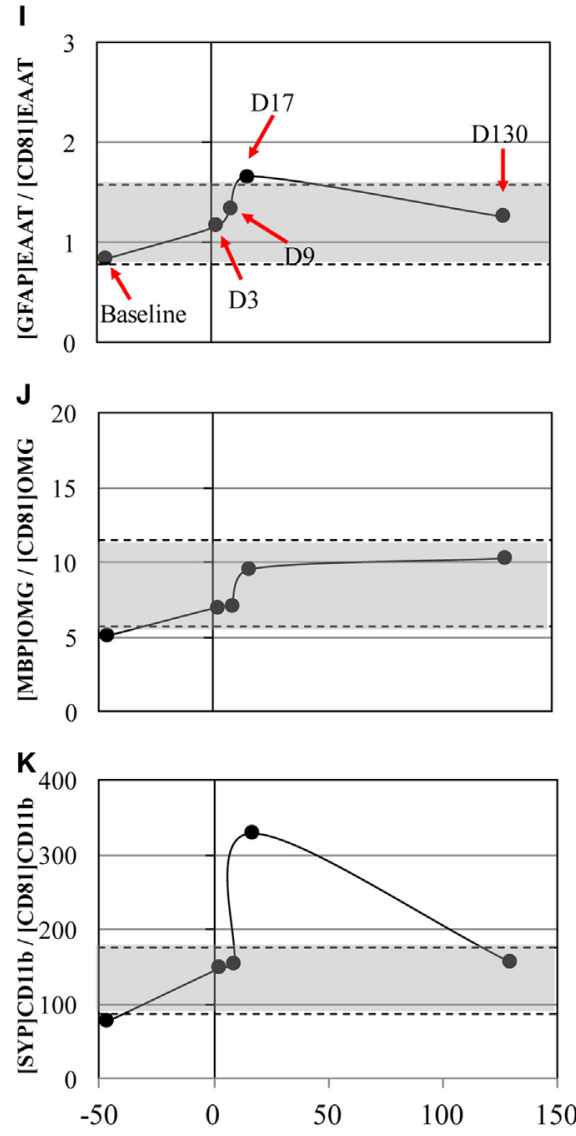

Days before and after concussion

Days before and after concussion

FIGURE 1 | Concussion case 1: transient symptoms. $X$ axis is days before and after concussion, with day 0 being the day of concussion. (A): clinical assessment of balance error scoring system (BESS) $(\bullet)$ and near point of convergence (NPC) $(\Delta)$. (B): [CD81 $]_{\text {SNAP25+ }}(\mathrm{U} / \mathrm{mL})$, (C): [CD81 $]_{\text {EAAT1+ }}(\mathrm{U} / \mathrm{mL}),(\mathbf{D})$ : [CD81 $]_{\text {oMG }}(\mathrm{U} / \mathrm{mL})$,

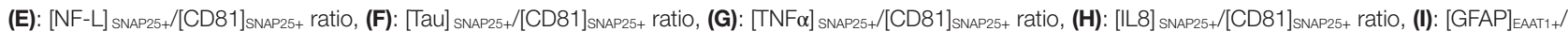

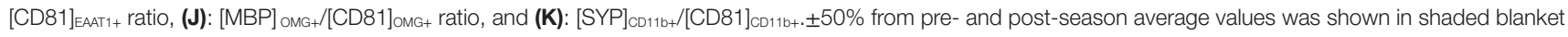
as referential values. SNAP25, synaptosome-associated protein 25, NF-L, neurofilament light polypeptide; TNF $\alpha$, tumor necrosis factor-alpha; IL8, interleukin-8; EAAT1, excitatory amino acid transporter 1; GFAP, glial fibrillary acidic protein; OMG, oligodendrocyte myelin glycoprotein; MBP, myelin basic protein; SYP, synaptophysin.

numerous cytosolic proteins adhere on the surface of the vesicles. These vesicles become exosomes when they merge with the cell membrane and release into the extracellular space (33).

The increases in NF-L and Tau markers suggest axonal injury, whereas the increases in TNF $\alpha$ and IL8 markers are due to neuroinflammation. The increases in GFAP and MBP markers are indicative of the activation of astrocytes and oligodendrocytes as a part of cellular repairing process, as well as apoptotic cell death in glial cells. The elevation in $[\mathrm{SYP}]_{\mathrm{CD} 1 \mathrm{~b}+} /[\mathrm{CD} 81]_{\mathrm{CD} 1 \mathrm{~b}+}$ means that microglia phagocytosis damaged neurons, generating microglia-derived exosomes containing neuron-specific marker, synaptophysin. The changes in biomarker levels between preand post-season are worthy of note, although all markers did not reach statistical significance due to its small sample size and after Bonferroni correction to account for multiple comparison. One potential reason that there was unremarkable increase 

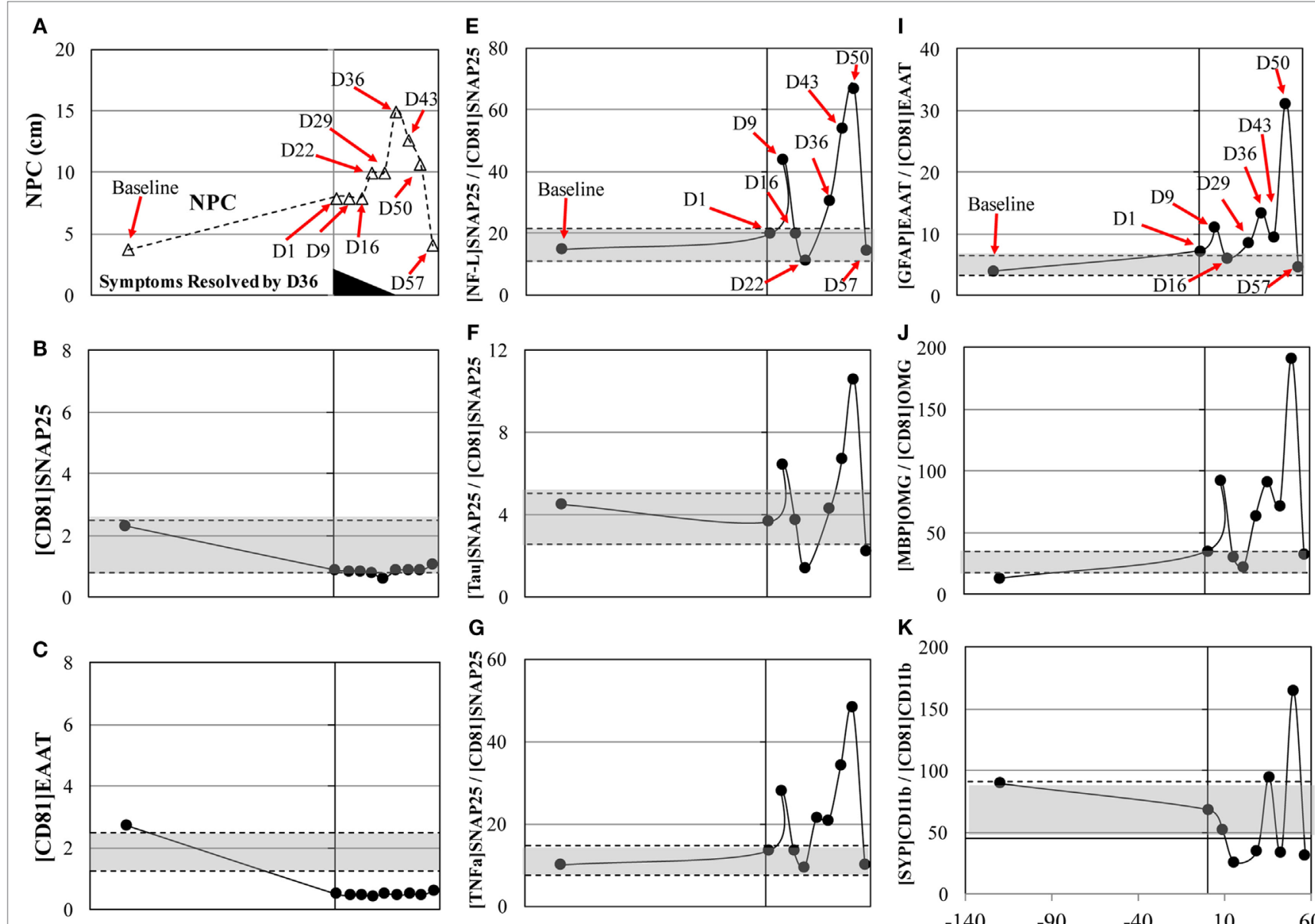

G
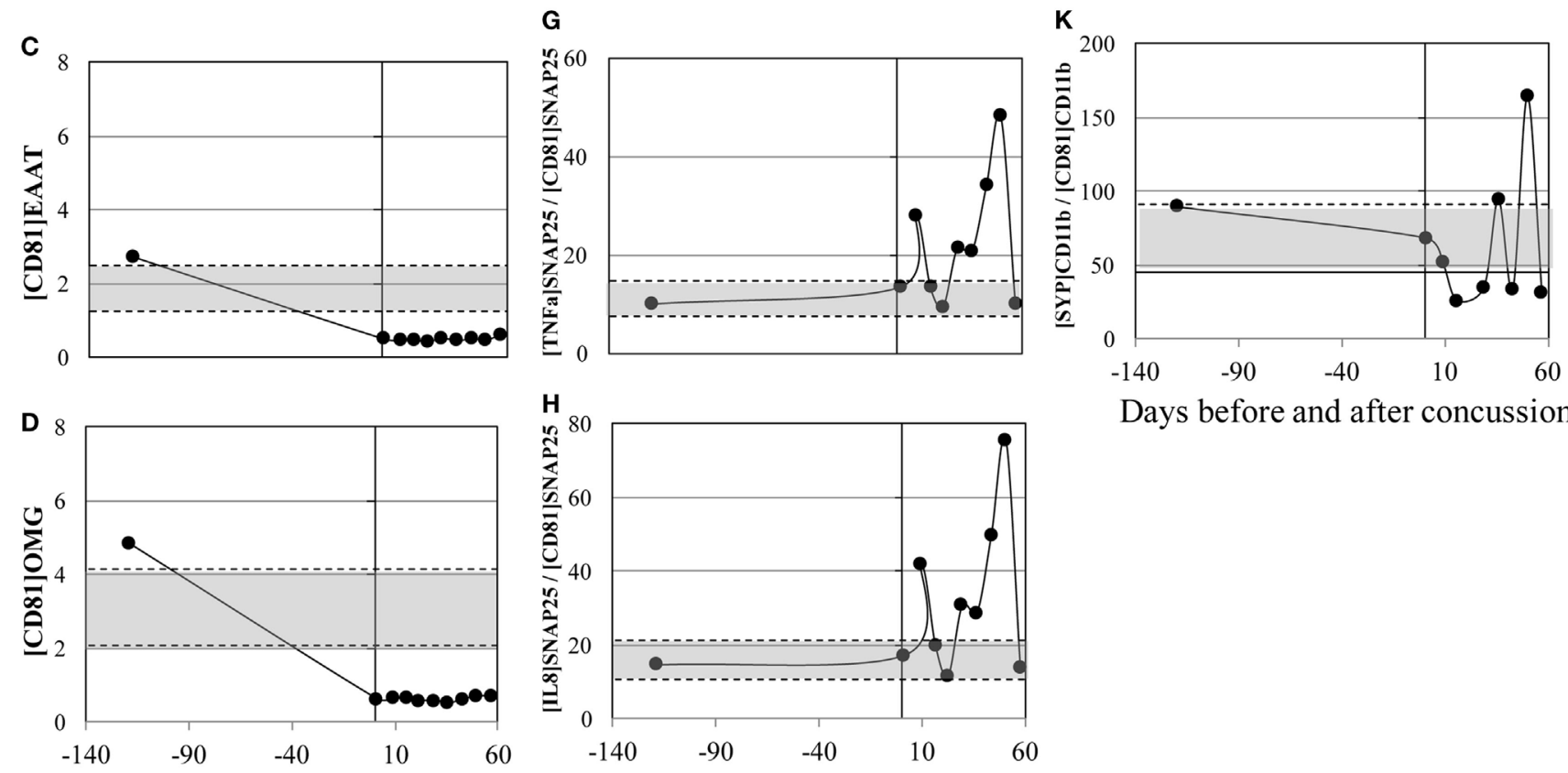

Days before and after concussion

Days before and after concussion

Days before and after concussion

FIGURE 2 | Concussion case 2: persisted symptoms. $X$ axis is days before and after concussion, with day 0 being the day of concussion. (A): clinical assessment of near point of convergence (NPC) $(\Delta)$.(B): [CD81 $]_{\text {SNAP25+ }}(\mathrm{U} / \mathrm{mL})$, (C): [CD81 $]_{\text {EAAT1+ }}(\mathrm{U} / \mathrm{mL})$, (D): [CD81 $]_{\text {oMG }}(\mathrm{U} / \mathrm{mL}),(\mathbf{E})$ : [NF-L $]_{\text {SNAP25 }} /[\mathrm{CD} 81]_{\text {SNAP25+ }}$ ratio, (F): [Tau]

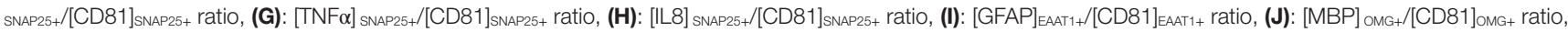
and (K): [SYP $]_{\mathrm{CD} 11 \mathrm{~b}+} /[\mathrm{CD} 81]_{\mathrm{CD11b+}}++50 \%$ from pre- and post-season average values was shown in shaded blanket as referential values. SNAP25, synaptosomeassociated protein 25, NF-L, neurofilament light polypeptide; TNF $\alpha$, tumor necrosis factor-alpha; IL8, interleukin-8; EAAT1, excitatory amino acid transporter 1; GFAP, glial fibrillary acidic protein; OMG, oligodendrocyte myelin glycoprotein; MBP, myelin basic protein; SYP, synaptophysin.

in the post-season biomarker data of the concussion subjects (\#3 and 6) was because these players sufficiently rested without incurring subconcussive head impacts. Particularly for the case 2, his concussion occurred toward the end of the season. His postseason data point corresponds to the 57-day post-concussion time point. During this recovery time, he did not participate in any activity involving head impacts. Therefore, his post-season biomarker values were normalized to the baseline level after resting for close to 2 months (Figure 2). On the contrary, his teammates ( $n=7$ including concussion case \#1) continued to engage in practices and games until the end of season, experiencing head and body impacts. Therefore, albeit statistically non-significant, there was an increase in the absolute value of neuron-related biomarker profile at post-season compared to 

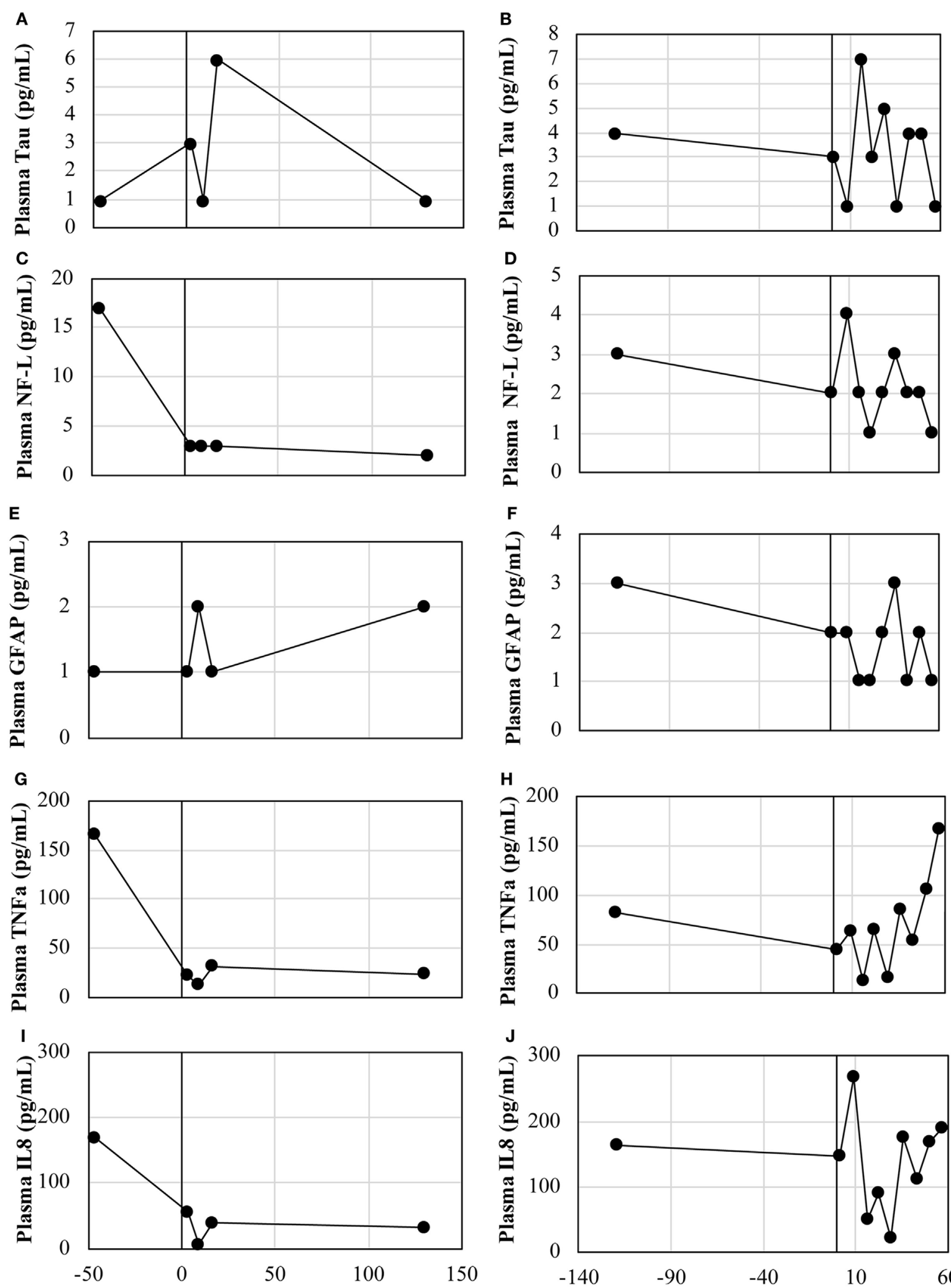

Days before and after concussion

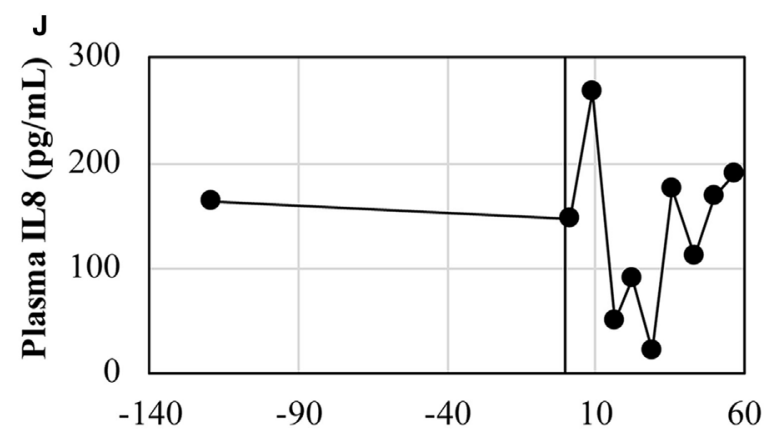

Days before and after concussion

FIGURE 3 | Serum levels of conventional protein biomarkers. Case 1: (A) Tau, (B) NF-L, (C) GFAP, (D) TNF $\boldsymbol{\alpha}$, and (E) IL8. Case 2: (F) Tau, (G) NF-L, (H) GFAP, (I) TNF $\alpha$, and (J) IL8. NF-L, neurofilament light polypeptide; TNF $\alpha$, tumor necrosis factor-alpha; IL8, interleukin-8; GFAP, glial fibrillary acidic protein. 
the pre-season baseline. To examine the effect of subconcussive head impacts, we are currently analyzing the array of our markers in high school football players from 12 different time points in a season, in relation to the frequency and magnitude of head impacts measured by accelerometer-installed mouth guard $(23,34,35)$.

There are several key limitations in the study. Our sandwich ELISA assays are not directly measuring exosomes, rather we normalized the double-positive signals specific to brain parenchymal cells by exosome signals. This way, we eliminated a number of steps required to isolate exosomes that are inherent to increased technical errors and cost (36). On the contrary, our sandwich ELISA technique is reliable, time saving, and cost effective, and thus, it is feasible for clinical testing. While results from the aforementioned cases are fascinating, a lack of sample size and data regarding head impact kinematics during the hockey season substantially hinder our interpretation of increased biomarker levels. Moreover, we did not have blood samples from concussion-free control subjects such as teammates, corresponding to the recovery time points of the concussion subjects. Due to the lack of these samples accounting for the effects of sub-clinical head impacts (e.g., subconcussive head impacts), we were unable to make a meaningful interpretation of the biphasic increase observed in the concussion case 2. Thus, it is imperative to validate the current findings in a larger sample size with appropriate control groups in conjunction with identifying sensitivity and specificity of these panels of biomarkers. Additional limitation is that although the within-subject stability of all exosome markers was excellent, there was between-subject disparity, suggesting the limited applicability for cross-sectional studies. On the contrary, the results have a tremendous implication in longitudinal assessments, where changes in biomarker levels from baseline level can be tracked over time to aid physicians to determine return-to-play/work, establish a threshold for cumulative forces to the head, and monitor the progression of neurodegenerative pathology. Finally, it is well-accepted notion that cerebral spinal fluid (CSF) biomarkers are superior in reflecting the severity and prognostication of brain trauma with higher sensitivity and specificity and longer half-life than those of blood-based biomarkers (37). Brain-derived factors not only cross breached blood-brain barrier into the blood stream but also are drained into subarachnoid space via the glymphatic system (7). Fraction of CSF markers is further drained into the blood stream through subclavian veins via lymphatic ducts, indicating that elevated biomarker levels in the blood are often derivative of CSF biomarkers. However, because of an invasive nature of the CSF marker assessment, an alternative approach including protein-based and exosome blood biomarkers is feasible in concussion cohort.

In summary, the present study suggests that a unique panel of blood biomarkers that may have the potential to surrogate chronic neural damage caused by sport-related concussion. Elevations in the blood biomarkers in this study were in line with the reports from chronic traumatic encephalopathy, Alzheimer's disease, and dementia patients (38-40), although remotely at this point. The current study serves as an excellent initial step to employ potential exosome biomarkers as a means to objectively monitor concussed patients' recovery.

\section{ETHICS STATEMENT}

This study was carried out in accordance with the recommendations of The University of Louisiana Lafayette, Institutional Review Board committee with written informed consent from all subjects. All subjects gave written informed consent in accordance with the Declaration of Helsinki. The protocol was approved by The University of Louisiana Lafayette Institutional Review Board.

\section{AUTHOR CONTRIBUTIONS}

KK and RA conceptualized and designed the study and the data collection instruments, collected data, drafted the initial manuscript, and reviewed and revised the manuscript. RA conceptualized and designed the study, collected data, and reviewed and revised the manuscript. MM conducted the experiments, interpreted the analysis, and critically reviewed the manuscript for important intellectual content. All the authors have read and approved the final manuscript as submitted and agree to be accountable for all aspects of the work.

\section{ACKNOWLEDGMENTS}

The authors would like to thank Dr. Stephanie N. Aldret for her assistance in data collection. This work was partly supported by the Indiana Spinal Cord \& Brain Injury Research Fund from the Indiana State Department of Health (to K. Kawata: ISCBIRF 0019939). Sponsors had no role in the design or execution of the study; collection, management, analysis, or interpretation of the data; preparation, review, or approval of the manuscript; or decision to submit the manuscript for publication.

\section{SUPPLEMENTARY MATERIAL}

The Supplementary Material for this article can be found online at https://www.frontiersin.org/articles/10.3389/fneur.2018.00239/ full\#supplementary-material.

FIGURE S1 | The results of dilution study of standard plasma. ELISA readings (RLU) (Y-axis) were converted to units per millilitre (X-axis) by assigning the standard plasma as $100 \mathrm{U} / \mathrm{mL}$. (A) $[\mathrm{CD} 81]_{\text {SNAP } 25+}$, (B) $[\mathrm{CD} 81]_{\text {EAAT1+ }}$, (C) $[\mathrm{CD} 81]_{\mathrm{OMG}+}$, (D) $[\mathrm{SYP}]_{\mathrm{CD} 11 \mathrm{~b}+}$, (E) $[\mathrm{Tau}]_{\mathrm{SNAP} 25+}$, (F) $[\mathrm{NF}-\mathrm{L}]_{\mathrm{SNAP} 25+}$, (G) $[\mathrm{TNF}]_{\mathrm{SNAP} 25+}$, (H) $[\mathrm{IL} 8]_{\text {SNAP25+ }}$, (I) [GFAP $]_{\text {EAAT } 1+}$, and (J) [MBP] $]_{\text {OMG. }}$. SNAP25, synaptosomeassociated protein 25, NF-L, neurofilament light polypeptide; TNF $\alpha$, tumor necrosis factor-alpha; IL8, interleukin-8; EAAT1, excitatory amino acid transporter 1; GFAP, glial fibrillary acidic protein; OMG, oligodendrocyte myelin glycoprotein; MBP, myelin basic protein; SYP, synaptophysin; RLU, relative light units.

FIGURE S2 | Fluctuation of plasma levels of NDE and surface biomarkers on neuronal markers. (A) [CD81 $]_{\text {SNAP25+ }}(\mathrm{U} / \mathrm{mL}),(\mathbf{B})[\mathrm{NF}-\mathrm{L}]_{\text {SNAP } 25+}(\mathrm{U} / \mathrm{mL}),(\mathbf{C})[\mathrm{NF}-\mathrm{L}]$ SNAP25+/[CD81 $]_{\text {SNAP25+ }}$ ratio, (D) $[\mathrm{Tau}]_{\text {SNAP25+ }}(\mathrm{U} / \mathrm{mL}),(\mathbf{E})[\mathrm{Tau}]_{\text {SNAP25+/ }} /[\mathrm{CD} 81]_{\text {SNAP } 25+}$ ratio, (F) $[T N F \alpha]_{\text {SNAP25+ }}(\mathrm{U} / \mathrm{mL}),(\mathbf{G})[T N F \alpha]_{\text {SNAP } 25+} /[\mathrm{CD} 81]_{\text {SNAP } 25+}$ ratio, (H) $[\mathrm{IL} 8]_{\mathrm{CD} 81+\text { SNAP } 25+}(\mathrm{U} / \mathrm{mL})$, and (I) [IL8 $]_{\text {SNAP } 25+/[\mathrm{CD} 81]_{\text {SNAP } 25+} \text { ratio. Each symbol }}$ represents a single individual. SNAP25, synaptosome-associated protein 25, NF-L, neurofilament light polypeptide; TNF $\alpha$, tumor necrosis factor-alpha; IL8, interleukin-8; EAAT1, excitatory amino acid transporter 1; GFAP, glial fibrillary acidic protein; OMG, oligodendrocyte myelin glycoprotein; MBP, myelin basic protein; SYP, synaptophysin. 
FIGURE S3 | Fluctuation of plasma levels of glial markers. (A) [CD81] EAAT1+ (U/mL), (B) [GFAP] $]_{\text {EAT1+ }}(\mathrm{U} / \mathrm{mL})$, (C) [GFAP] $]_{\text {EAT1+ }} /[\mathrm{CD} 81]_{\text {EAAT1+ }}$ ratio, (D) [CD81 $]_{\text {омG }}(\mathrm{U} / \mathrm{mL}),(\mathbf{E})[\mathrm{MBP}]_{\text {омG }},(\mathrm{U} / \mathrm{mL}),(\mathbf{F})[\mathrm{MBP}]_{\text {омG }} /[\mathrm{CD} 81]_{\text {омG }}$ ratio, and (G) $[S Y P]_{C D 11 b+} /[C D 81]_{C D 11 b+}$. Each symbol represents a single

\section{REFERENCES}

1. Leddy JJ, Sandhu H, Sodhi V, Baker JG, Willer B. Rehabilitation of concussion and post-concussion syndrome. Sports Health (2012) 4(2):147-54. doi:10.1177/1941738111433673

2. McCrory P, Meeuwisse W, Dvorak J, Aubry M, Bailes J, Broglio S, et al. Consensus statement on concussion in sport-the $5($ th) international conference on concussion in sport held in Berlin, October 2016. Br J Sports Med (2017) 51(11):838-47. doi:10.1136/bjsports-2017-097699

3. De Beaumont L, Brisson B, Lassonde M, Jolicoeur P. Long-term electrophysiological changes in athletes with a history of multiple concussions. Brain Inj (2007) 21(6):631-44. doi:10.1080/02699050701426931

4. Bazarian JJ, Zhu T, Zhong J, Janigro D, Rozen E, Roberts A, et al. Persistent, long-term cerebral white matter changes after sports-related repetitive head impacts. PLoS One (2014) 9(4):e94734. doi:10.1371/journal.pone.0094734

5. Johnson B, Hallett M, Slobounov S. Follow-up evaluation of oculomotor performance with fMRI in the subacute phase of concussion. Neurology (2015) 85(13):1163-6. doi:10.1212/WNL.0000000000001968

6. Zetterberg H, Smith DH, Blennow K. Biomarkers of mild traumatic brain injury in cerebrospinal fluid and blood. Nat Rev Neurol (2013) 9(4):201-10. doi:10.1038/nrneurol.2013.9

7. Kawata K, Liu CY, Merkel SF, Ramirez SH, Tierney RT, Langford D. Blood biomarkers for brain injury: what are we measuring? Neurosci Biobehav Rev (2016) 68:460-73. doi:10.1016/j.neubiorev.2016.05.009

8. Papa L, Lewis LM, Silvestri S, Falk JL, Giordano P, Brophy GM, et al. Serum levels of ubiquitin C-terminal hydrolase distinguish mild traumatic brain injury from trauma controls and are elevated in mild and moderate traumatic brain injury patients with intracranial lesions and neurosurgical intervention. J Trauma Acute Care Surg (2012) 72(5):1335-44. doi:10.1097/ TA.0b013e3182491e3d

9. Kiechle K, Bazarian JJ, Merchant-Borna K, Stoecklein V, Rozen E, Blyth B, et al. Subject-specific increases in serum S-100B distinguish sports-related concussion from sports-related exertion. PLoS One (2014) 9(1):e84977. doi:10.1371/journal.pone.0084977

10. Shahim P, Tegner Y, Wilson DH, Randall J, Skillback T, Pazooki D, et al. Blood biomarkers for brain injury in concussed professional ice hockey players. JAMA Neurol (2014) 71(6):684-92. doi:10.1001/jamaneurol.2014.367

11. Olivera A, Lejbman N, Jeromin A, French LM, Kim HS, Cashion A, et al. Peripheral total Tau in military personnel who sustain traumatic brain injuries during deployment. JAMA Neurol (2015) 72(10):1109-16. doi:10.1001/ jamaneurol.2015.1383

12. Siman R, Shahim P, Tegner Y, Blennow K, Zetterberg H, Smith DH. Serum SNTF increases in concussed professional ice hockey players and relates to the severity of postconcussion symptoms. J Neurotrauma (2015) 32(17):1294-300. doi:10.1089/neu.2014.3698

13. Papa L, Brophy GM, Welch RD, Lewis LM, Braga CF, Tan CN, et al. Time course and diagnostic accuracy of glial and neuronal blood biomarkers GFAP and UCH-L1 in a large cohort of trauma patients with and without mild traumatic brain injury. JAMA Neurol (2016) 73(5):551-60. doi:10.1001/ jamaneurol.2016.0039

14. Papa L, Mittal MK, Ramirez J, Silvestri S, Giordano P, Braga CF, et al. Neuronal biomarker ubiquitin C-terminal hydrolase (UCH-L1) detects traumatic intracranial lesions on CT in children and youth with mild traumatic brain injury. J Neurotrauma (2017) 34(13):2132-40. doi:10.1089/ neu.2016.4806

15. Shahim P, Zetterberg H, Tegner Y, Blennow K. Serum neurofilament light as a biomarker for mild traumatic brain injury in contact sports. Neurology (2017) 88(19):1788-94. doi:10.1212/WNL.0000000000003912

16. Shahim P, Gren M, Liman V, Andreasson U, Norgren N, Tegner Y, et al. Serum neurofilament light protein predicts clinical outcome in traumatic brain injury. Sci Rep (2016) 6:36791. doi:10.1038/srep36791

17. Thelin EP, Zeiler FA, Ercole A, Mondello S, Buki A, Bellander BM, et al. Serial sampling of serum protein biomarkers for monitoring human traumatic brain individual. NF-L, neurofilament light polypeptide; TNF $\alpha$, tumor necrosis factor-alpha; IL8, interleukin-8; EAAT1, excitatory amino acid transporter 1; GFAP, glial fibrillary acidic protein; OMG, oligodendrocyte myelin glycoprotein; MBP, myelin basic protein; SYP, synaptophysin.

injury dynamics: a systematic review. Front Neurol (2017) 8:300. doi:10.3389/ fneur.2017.00300

18. Pant $\mathrm{S}$, Hilton H, Burczynski ME. The multifaceted exosome: biogenesis, role in normal and aberrant cellular function, and frontiers for pharmacological and biomarker opportunities. Biochem Pharmacol (2012) 83(11):1484-94. doi:10.1016/j.bcp.2011.12.037

19. Vlassov AV, Magdaleno S, Setterquist R, Conrad R. Exosomes: current knowledge of their composition, biological functions, and diagnostic and therapeutic potentials. Biochim Biophys Acta (2012) 1820(7):940-8. doi:10.1016/j. bbagen.2012.03.017

20. Nekludov M, Bellander BM, Gryth D, Wallen H, Mobarrez F. Brain-derived microparticles in patients with severe isolated TBI. Brain Inj (2017) 31(13-14): 1856-62. doi:10.1080/02699052.2017.1358395

21. Yoshioka Y, Konishi Y, Kosaka N, Katsuda T, Kato T, Ochiya T. Comparative marker analysis of extracellular vesicles in different human cancer types. J Extracell Vesicles (2013) 2:20424. doi:10.3402/jev.v2i0.20424

22. Andreu Z, Yanez-Mo M. Tetraspanins in extracellular vesicle formation and function. Front Immunol (2014) 5:442. doi:10.3389/fimmu.2014. 00442

23. Kawata K, Rubin LH, Lee JH, Sim T, Takahagi M, Szwanki V, et al. Association of football subconcussive head impacts with ocular near point of convergence. JAMA Ophthalmol (2016) 134(7):763-9. doi:10.1001/jamaophthalmol. 2016.1085

24. Kawata K, Tierney R, Phillips J, Jeka JJ. Effect of repetitive sub-concussive head impacts on ocular near point of convergence. Int J Sports Med (2016) 37(5):405-10. doi:10.1055/s-0035-1569290

25. Bell DR, Guskiewicz KM, Clark MA, Padua DA. Systematic review of the balance error scoring system. Sports Health (2011) 3(3):287-95. doi:10.1177/ 1941738111403122

26. Shrout PE, Fleiss JL. Intraclass correlations: uses in assessing rater reliability. Psychol Bull (1979) 86(2):420-8. doi:10.1037/0033-2909.86.2.420

27. Broglio SP, Ferrara MS, Macciocchi SN, Baumgartner TA, Elliott R. Test-retest reliability of computerized concussion assessment programs. JAthl Train (2007) 42(4):509-14.

28. Zhang H, Duan L, Zhang YJ, Lu CM, Liu H, Zhu CZ. Test-retest assessment of independent component analysis-derived resting-state functional connectivity based on functional near-infrared spectroscopy. Neuroimage (2011) 55(2):607-15. doi:10.1016/j.neuroimage.2010.12.007

29. Landis JR, Koch GG. The measurement of observer agreement for categorical data. Biometrics (1977) 33(1):159-74. doi:10.2307/2529310

30. McCrea M, Guskiewicz KM, Marshall SW, Barr W, Randolph C, Cantu RC, et al. Acute effects and recovery time following concussion in collegiate football players: the NCAA concussion study. JAMA (2003) 290(19):2556-63. doi:10.1001/jama.290.19.2556

31. Leddy JJ, Baker JG, Willer B. Active rehabilitation of concussion and post-concussion syndrome. Phys Med Rehabil Clin N Am (2016) 27(2):437-54. doi:10.1016/j.pmr.2015.12.003

32. Zhang X, Yuan X, Shi H, Wu L, Qian H, Xu W. Exosomes in cancer: small particle, big player. J Hematol Oncol (2015) 8:83. doi:10.1186/s13045-0150181-x

33. Gruenberg J, van der Goot FG. Mechanisms of pathogen entry through the endosomal compartments. Nat Rev Mol Cell Biol (2006) 7(7):495-504. doi:10.1038/nrm1959

34. Kawata K, Rubin LH, Takahagi M, Lee JH, Sim T, Szwanki V, et al. Subconcussive impact-dependent increase in plasma S100beta levels in collegiate football players. JNeurotrauma (2017) 34(14):2254-60. doi:10.1089/neu. 2016.4786

35. Kawata K, Rubin LH, Wesley L, Lee J, Sim T, Takahagi M, et al. Acute changes in plasma total Tau levels are independent of subconcussive head impacts in college football players. J Neurotrauma (2018) 35(2):260-6. doi:10.1089/ neu.2017.5376

36. Li P, Kaslan M, Lee SH, Yao J, Gao Z. Progress in exosome isolation techniques. Theranostics (2017) 7(3):789-804. doi:10.7150/thno.18133 
37. Agoston DV, Shutes-David A, Peskind ER. Biofluid biomarkers of traumatic brain injury. Brain Inj (2017) 31(9):1195-203. doi:10.1080/02699052.2017.1357836

38. Goetzl EJ, Boxer A, Schwartz JB, Abner EL, Petersen RC, Miller BL, et al. Altered lysosomal proteins in neural-derived plasma exosomes in preclinical Alzheimer disease. Neurology (2015) 85(1):40-7. doi:10.1212/ WNL.0000000000001702

39. Goetzl EJ, Kapogiannis D, Schwartz JB, Lobach IV, Goetzl L, Abner EL, et al. Decreased synaptic proteins in neuronal exosomes of frontotemporal dementia and Alzheimer's disease. FASEB J (2016) 30(12):4141-8. doi:10.1096/ f. $201600816 \mathrm{R}$

40. Stern RA, Tripodis Y, Baugh CM, Fritts NG, Martin BM, Chaisson C, et al. Preliminary study of plasma exosomal Tau as a potential biomarker for chronic traumatic encephalopathy. J Alzheimers Dis (2016) 51(4):1099-109. doi:10.3233/JAD-151028

Conflict of Interest Statement: KK and RA report no competing financial interests. MM is an employee of NanoSomiX, Inc.

Copyright $\odot 2018$ Kawata, Mitsuhashi and Aldret. This is an open-access article distributed under the terms of the Creative Commons Attribution License (CC BY). The use, distribution or reproduction in other forums is permitted, provided the original author(s) and the copyright owner are credited and that the original publication in this journal is cited, in accordance with accepted academic practice. No use, distribution or reproduction is permitted which does not comply with these terms. 